\title{
DÜBLIN
}

Technological University Dublin

ARROW@TU Dublin

\section{Short-term electricity load forecasting for the integrated single electricity market (I-SEM)}

\author{
Katie Kavanagh \\ Technological University Dublin \\ Martin Barrett \\ Technological University Dublin, martin.barrett@tudublin.ie \\ Michael Conlon \\ Technological University Dublin, michael.conlon@tudublin.ie
}

Follow this and additional works at: https://arrow.tudublin.ie/engscheleart

Part of the Electrical and Computer Engineering Commons

\section{Recommended Citation}

K. Kavanagh, M. Barrett and M. Conlon, "Short-term electricity load forecasting for the integrated single electricity market (I-SEM)," 2017 52nd International Universities Power Engineering Conference (UPEC), 2017, pp. 1-7, doi: 10.1109/UPEC.2017.8231994.

This Conference Paper is brought to you for free and open access by the School of Electrical and Electronic Engineering at ARROW@TU Dublin. It has been accepted for inclusion in Conference papers by an authorized administrator of ARROW@TU Dublin. For more information, please contact arrow.admin@tudublin.ie, aisling.coyne@tudublin.ie,gerard.connolly@tudublin.ie.

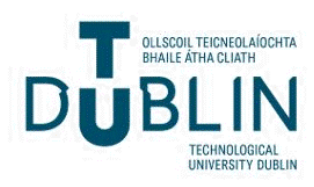




\section{Short-Term Electricity Load Forecasting for the Integrated Single Electricity Market (I-SEM)}

\author{
Katie Kavanagh \\ Dublin Institute of Technology \\ Ireland \\ D15125143@mydit.ie
}

\author{
Dr. Martin Barrett \\ Dublin Institute of Technology \\ Ireland \\ Martin.Barret@dit.ie
}

\author{
Prof. Michael Conlon \\ Dublin Institute of Technology \\ Ireland \\ Michael.Conlon@dit.ie
}

\begin{abstract}
The electricity market structure in Ireland is being reconstructed in order to meet with the requirements of the $\mathrm{EU}$ Third Energy Package. The forthcoming Integrated-Single Electricity Market (I-SEM) differs from the current market structure in many ways. However this research addresses the issue of balance responsibility under the I-SEM. Given the volatility of prices in the Balancing market, observed in similarly-structured markets around the world, Irish supply companies need to be able to accurately forecast their customers' load in the Day-Ahead market in order to manage risk in the Balancing market. This paper presents a means for suppliers to implement short-term load forecasting (STLF) of electricity. A Neural Network model is used as well as a Double Seasonal Exponential Smoothing variation of the Holt-Winters method. Data from the Irish market was used to forecast a supply company's load as well as the national load, using these methods. Measured by MAPE (mean absolute percentage error), both methods produced positive results of below $3 \%$. It is envisaged that with these results, a supply company operating in the Irish market should be able to apply these forecasting methods to their historical customer data to submit modestly accurate bids, with the intention of securing their position in the Day-Ahead market and reducing the potential of any financial implications accruing in the Balancing market.
\end{abstract}

Index Terms - Artificial Neural Networks, Demand Forecasting, Holt-Winters Exponential Smoothing, MATLAB, STLF.

\section{INTRODUCTION}

In May of 2018, the current electricity market in Ireland (the Republic of Ireland and Northern Ireland), the Single Electricity Market or the SEM, is set to undergo significant changes and become the Integrated Single Electricity Market or I-SEM [1]. There are many differences in the structure of the SEM and I-SEM. This paper addresses the change of balance responsibility and what this will mean for Irish supply companies in terms of forecasting their customer load.
A means for accurately forecasting short-term electricity demand, suitable to the Irish market, will be presented.

In this context, short-term load forecasts refer to periods ranging from a one hour lead time to a week ahead. This research considers forecasting loads for half hourly lead times for a day (24 hours) ahead.

\section{A. The I-SEM}

The new market structure was developed as a means for creating a more competitive market place to ensure economic strength and the prevention of a stale and static market, and for the purpose of establishing an electricity market that is conducive with the European internal market, the European Target Model (ETM) and the corresponding EU goals. Such goals revolve around the aims of eventually creating a level playing field for the efficient use of cross-border capacity and of harmonised EU electricity markets.

The I-SEM, while fulfilling requirements to be on track toward the ETM, will answer issues that have risen from the SEM, as a result of changes in demand, generation and interconnection.

The SEM Committee has assessed that the I-SEM High Level Design (HLD) will best deliver the benefits of European market integration in terms of:

- Security of supply

- Promotion of renewable energy sources

- Establishment of a level playing field in which competition can flourish

- Maximise the efficient use of interconnectors

- Provision of a sound investment climate that is based upon a stable and predictable regulatory framework [2] 
B. What this Means for Participants

Under the structure of the I-SEM, there will be multiple markets running across different timeframes to accommodate trading. These markets include a Forwards market, physical trading markets including a Day-Ahead market, an Intraday market and a Balancing market, and imbalance settlement. The position of an individual generator or supplier will be determined by their trading activity across the various markets of the I-SEM. In the new market, all parties (generators and suppliers) will be balance responsible. This means that the respective parties will be responsible for any discrepancies between the Day-Ahead market and Intraday market trades they make, and the actual metered quantities they produce or take. This results in mandatory participation in the Balancing market and any subsequent imbalance settlements to fine-tune promised production and consumption trades. Notably, generators and suppliers will want to manage their bid quantities in the different markets, in order to avoid exposure to the price differences between the Day-Ahead and Imbalance markets. To do so, these companies need to have their bids as accurate as possible in the Day-Ahead market [3]. This will require a reliable forecasting method for supply companies.

A literature review was carried out to identify suitable forecasting methods for a supply company in the I-SEM. Many methods were identified, but a variation of the Double Seasonal Holt-Winters Exponential Smoothing with Error Correction method and a Neural Network model were deemed likely to be the most suitable and were tested. These methods were chosen and tested because of the inputs they require and their availability, how user-friendly the methods are, and lastly, because of the success of these types of models in other cases.

\section{Literature ReView}

Electricity load forecasting and short-term load forecasting (STLF) have been around for many decades given the need for these measures in the industry. Forecasting has been crucial to ensuring reliable, economical and secure energy systems. Over the years many methods of STLF have been developed and put in place in markets across the globe.

Recent trends in STLF include concise techniques such as Statistical methods and Artificial Intelligence models as well as more elaborate methods including Knowledge-Based Expert Systems and Hybrid Techniques [4].

Statistical models are used to identify the relationship between the load and combinations of input factors. Common statistical methods include Multiple Regression analysis, Exponential Smoothing, Stochastic Time Series and Iteratively Reweighted Least Squares.

Computationally, Multiple Regression involves fitting a curve through data plots of the relationship between input and load to identify a pattern and forecast. Similarly, the Iteratively Reweighted Least Squares method uses past load data to create a model. Weighting functions, tuning constants and the weighted sum of the squared residuals are used to determine a model and correlating parameter estimates [5].

Stochastic Time Series methods require a random probability distribution. These time series methods include Autoregressive (AR), Autoregressive Moving Average (ARMA) and Autoregressive Integrated Moving Average (ARIMA). Time Series methods are popular choices for forecasting, however they can be time consuming to implement and require data that are complex and constantly changing.

Lastly, Exponential Smoothing methods are another popular option in STLF. With these types of methods, historical data are modelled and smoothed, and forecasts are developed with these models. These models can account for factors such as fitting functions, seasonal patterns, level and trend.

A recent research review [4] suggests that Artificial Intelligence Models including Fuzzy Logic, Artificial Neural Networks (ANN) and Genetic Algorithms have also recently become common means of STLF.

Fuzzy Logic methods use expert systems to apply an operator's heuristic knowledge to input data and update forecasts in the very short-term, a few hours [6]. This method requires detailed and regular analysis of the data and can be quite time consuming [7]. Literature has shown that despite the drawbacks, fuzzy logic methods can be effective in shortterm load forecasting.

Neural Networks are another type of Artificial Intelligence model. As the name suggests, these models are modelled after the processes of the human brain. Data are received, aggregated and then processed in layers of neurons. The most commonly applied Neural Network model for electricity forecasting is the feed-forward type [4]. These models combine multiple layers of neurons, but with only one input layer and one output layer. This paper also evidences that often times Neural Networks and Fuzzy Logic methods are used together to make load forecasts with considerable 
success. However, Neural Networks on their own provide good results [8].

Breaching elaborate methods, Genetic Algorithms (GA) build on the ideas of Neural Network methods. GA methods are models that imitate biological evolution and the idea of the survival of the fittest for a structured, random information exchange [9].

Knowledge-Based Expert Systems and Hybrid Techniques put in place complex and quite developed means of forecasting. Although they generally produce good results, these methods are time consuming and require many resources [10]. Knowledge-Based Expert Systems build on Artificial Intelligence and are rule-based methods that utilise experts' experience. Often they are used in conjunction with other methods, to fine-tune methods on non-normal days, such as days hosting large festivals and sporting events or unique weather occurrences. Hybrid methods typically involve the application of two methods regularly, such as an ANN and a GA [11].

Given the positive results of Neural Networks in other research and the availability of historical weather data it was decided to test this method on Irish data to see how it compares. A second method, Double Seasonal Holt-Winters Exponential Smoothing with Error Correction was chosen as well. This method combines traits from different established methods discussed in the Literature Review so it was hypothesised that the combination of time series and exponential smoothing would yield positive results.

\section{Methodology}

\section{A. Steps to Methodising Load Forecast}

Many steps were taken to establish the best method of forecasting electricity load in the Irish market. Firstly, data with which to test possible methods had to be collected. Second, data cleaning had to be undertaken. Then, forecasting methods had to be decided on for testing. After, selected methods were tested. Then, results were consistently measured and compared in order to better inform a forecasting plan.

\section{B. Data Collection \& Cleaning}

As this research was designed with the aim of using the findings in the I-SEM, Irish market data was desirable. Load data were collected from two sources, an electricity supply company operating in Ireland and serving commercial and industrial customers and the country's national load data (Republic of Ireland).
The load data for the supply company shows their customers' total electricity usage as one value, visualised as 48 half-hours per day for 15 months from 1st January 2013 to 31st March 2014. Fig. 1 shows the supplier load for the period of forecast.

The national data similarly are the total electricity used by the country. These data are also formatted as 48 half-hours per day, as the SEM - and soon the I-SEM - operates in half hour blocks for trading. The national data were obtained straight from the SEMO (Single Electricity Market Operator) website. Fig. 2 shows the system load for the period of forecast.

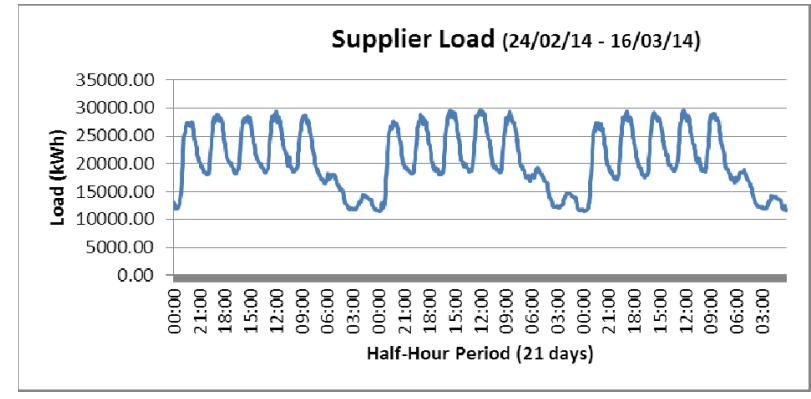

Fig. 1. One month supplier load in $\mathrm{kWh}$ from 24/02/14 - 16/03/14 for half-hour intervals

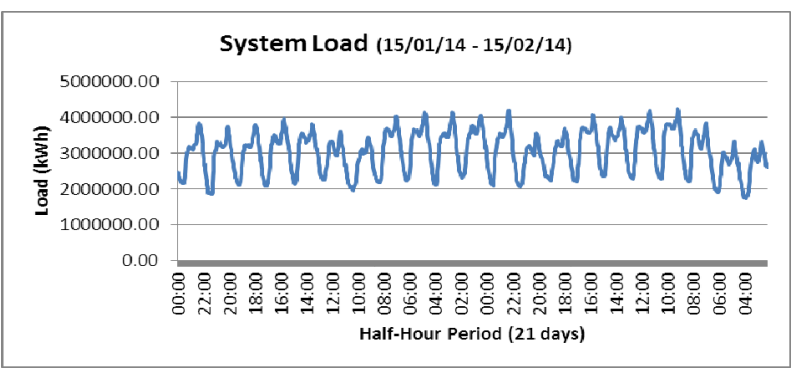

Fig. 2. One month system load in $\mathrm{kWh}$ from 24/02/14 - 16/03/14 for half-hour intervals

Data cleaning in this context meant smoothing out special days and accounting for any missing hours. Special days include days with irregular electricity consumption patterns such as holidays. Missing hours occurred as a result of changes in daylight saving. These steps were taken to create consistency in the seasonal data patterns (weekly and daily patterns) with the aim of improving forecast accuracy.

\section{Determining Forecasting Methods}

The methods were also assessed on such things as their accuracy in other contexts (i.e. other electricity markets) and how user-friendly they were. Inputs such as historical data and weather factors were taken into consideration, as well as their accessibility. 


\section{i. Holt-Winters}

Taylor [12] applies the theory in multiplicative seasonal ARIMA models with the Holt-Winters method to capture series with more than one seasonality, creating a Double Seasonal Exponential Smoothing method with Error Correction. This involves adding an additional seasonal index as well as an additional smoothing index to the original method. This method also introduces exponential smoothing, a common alternative to ARIMA models. For this research, the Holt-Winters forecast was modelled in Excel and then in MATLAB as the software is fast and efficient, and easily allows for revisions to be made.

The Holt-Winters method for double multiplicative seasonality is made up of a suite of formulae. This includes formulae for Level, Trend, Seasonality 1 (daily), Seasonality 2 (weekly) and the final forecasting equation (1)-(5).

$$
\begin{array}{ll}
\text { Level } & S_{t}=\alpha\left(X_{t} /\left(D_{t-s_{1}} W_{t-S_{2}}\right)\right)+(1-\alpha)\left(S_{t-1}+T_{t-1}\right) \\
\text { Trend } & T_{t}=\gamma\left(S_{t}-S_{t-1}\right)+(1-\gamma) T_{t-1} \\
\text { Season 1 } & D_{t}=\delta\left(X_{t} /\left(S_{t} W_{t-s_{2}}\right)\right)+(1-\delta) D_{t-S_{1}} \\
\text { Season 2 } & W_{t}=\omega\left(X_{t} /\left(S_{t} D_{t-S_{1}}\right)\right)+(1-\omega) W_{t-S_{2}} \\
& X_{t}(k)=\left(S_{t}+k T_{t}\right) D_{t-S_{1}+k} W_{t-S_{2}+k}
\end{array}
$$

Where $S$ is the Level, $X$ is the observed value (load), $D$ is the Daily Seasonality, $W$ is the Weekly Seasonality, $T$ is the Trend, $t$ is the period (continuous, not limited to the 48 halfhour cycle) and $k$ is the period within the 48 half-hour cycle. In the suite, $\alpha, \gamma, \delta$ and $\omega$ represent smoothing parameters.

The two seasonal indices are $D_{t}$, daily, and $W_{t}$, weekly. The first $s_{1}$-period seasonal index of the data set, $D_{t}$, is estimated by smoothing the ratio of observed value, $X_{t}$, to the product of the local level, $S_{t}$, and local $s_{2}$-period seasonal index, $W_{t-s_{2}}$. The first $s_{2}$-period seasonal index, $W_{t}$, is estimated by smoothing the ratio of observed value, $X_{t}$, to the product of the local level, $S_{t}$, and local $s_{1}$-period seasonal index, $D_{t-s_{1}}$. These are first calculated and then the formulae are applied to the data to prepare them for forecasting.

As the Irish market is broken up into 48 half-hour periods of demand per day, $s_{1}$ is set equal to 48 to represent a day and $s_{2}$ to 336 to represent a week.

Calculating the initial smoothed values for Level, Trend and the Seasonalities was the first step, as carried out by Taylor [12].

The initial trend, $T_{0}$, was calculated as the average of:
1. $1 / 336$ of the difference between the mean of the first 336 and second 336 observations, and,

2. The average of the first differences for the first 336 observations.

The initial level, $S_{0}$, was calculated as the mean of the first 672 observations minus 336.5 times the initial trend.

For $D_{\mathrm{t}}$, the initial within-day seasonality, value was set as the average of the ratios of actual observation to 48-point centred moving average, taken from the corresponding halfhour period in each of the first seven days of the data set.

For $W_{\mathrm{t}}$, the within-week seasonality, values were set as the average of the ratios of actual observation to 336-point centred moving average, taken from the corresponding halfhour period on the same day of the week in each of the first two weeks of the data set, divided by the corresponding initial value of the smoothed within-day seasonal index, $D_{\mathrm{t}}$.

Parameter estimation was undertaken for eight weeks of data (2,688 observations) to form forecasts.. The values for the smoothing parameters were gathered from a process of minimising the sum of squared one step-ahead forecast errors, using a non-linear optimisation method.

Error correction for the Double Seasonal Holt-Winters Exponential Smoothing was incorporated as the method shows results of first-order autocorrelation in the forecast. So to improve the forecast an error correction is used. To do this, the $\mathrm{k}$ step-ahead forecasts, from starting forecast point $t$, are adjusted by adding $\lambda^{k} e_{t}$, where $\lambda$ is an additional smoothing parameter and $e$ is the error at time, $t$.

\section{ii. Artificial Neural Network}

The second method employed was an Artificial Neural Network, executed in MATLAB. The same data sets that were used for the Holt-Winters method were used for the neural network in order to better compare results.

The training method used for this neural network was the Levenberg-Marquardt method, a backpropagation method. This involved steps carried out in MATLAB, with the Neural Network Toolbox, including:

1. Collecting data

2. Creating the network

3. Configuring the network

4. Initialising the weights and biases

5. Training the network

6. Validating the network and lastly; 
7. Using the network to make forecasts

While the Holt-Winters method used eight weeks of observations to train the data, the NN used a year of data training to create forecasts.

Input data for the NN consisted of historical load data as well as historical weather data. The purpose of this research is to test and propose a forecasting method that is easy for users to implement given the short-term time horizon. For this reason, the other inputs used for the NN forecast are historical weather data, gathered from the Met Eireann website. These data are easy to access and are available for a number of years.

Weather inputs consisted of the following: Maximum and Minimum Temperature $\left({ }^{\circ} \mathrm{C}\right)$, Air Temperature $\left({ }^{\circ} \mathrm{C}\right)$, Wet Bulb Temperature $\left({ }^{\circ} \mathrm{C}\right)$, Sunshine Hours, Dew Point Temperature $\left({ }^{\circ} \mathrm{C}\right)$ and Wind Speed (knots). However, the best combination consisted of Wet Bulb Temperature and Sunshine Hours in addition to the historical load data inputs Period, Day of the Week, Previous Week Same Hour Load, Previous Day Same Hour Load and Previous 24 Hour Average Load.

\section{Results AND DISCUSSION}

The Double Seasonal Holt-Winters Exponential Smoothing method with Error correction was applied with reasonable success. The average MAPE for each half-hour of the Supplier data was $2.17 \%$. The average MAPE for each half-hour of the National data was $4.5 \%$. These results were promising for the Supplier data, but the Neural Network method was applied to determine if an improved MAPE could be achieved, particularly for the National data.

Under the NN method, the Supplier data yielded a MAPE of $2.18 \%$. With this method, the MAPE for the National data was $2.35 \%$. Both methods gave promising results. When choosing a method to implement however, it is important to consider that the Neural Network model used a year of data to form forecasts, while the Holt-Winters variation used eight weeks of data. The methods' accuracy for the Supplier data is illustrated in Fig. 3.

Fig. 3 shows that both methods are very accurate when used on the supplier data. Each method has stronger points throughout the day. Taking the MAPEs for each half-hour period throughout the three weeks into consideration, the data show that the Holt-Winters method is moderately more accurate on Mondays and Thursdays and significantly more accurate on Sundays. The Neural Network method however shows superiority on Fridays and Saturdays in this case, as demonstrated in Table 1.

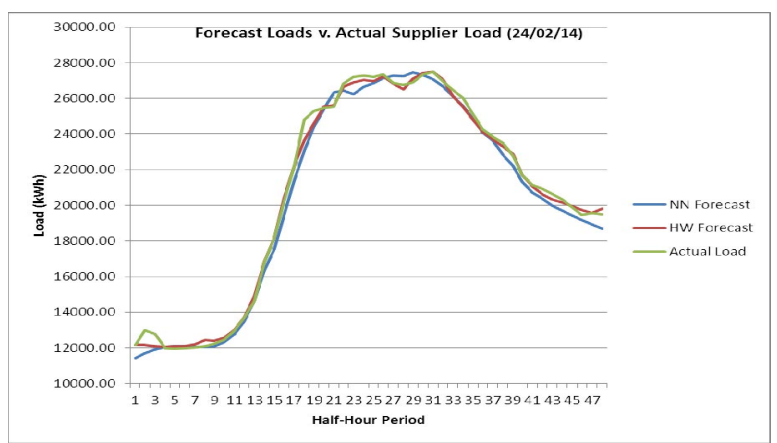

Fig. 3. Forecast methods v. actual load for a day $(24 / 02 / 14)$ in half-hour intervals

Table 1

SUPPLIER LOAD FORECAST METHOD COMPARISON

\begin{tabular}{|c|c|c|}
\hline & $\begin{array}{l}\text { Holt-Winters } \\
\text { MAPE }\end{array}$ & $\begin{array}{c}\text { NN } \\
\text { MAPE }\end{array}$ \\
\hline Monday & $1.91 \%$ & $2.33 \%$ \\
\hline Tuesday & $2.20 \%$ & $2.15 \%$ \\
\hline Wednesday & $1.89 \%$ & $1.82 \%$ \\
\hline Thursday & $1.94 \%$ & $2.10 \%$ \\
\hline Friday & $1.49 \%$ & $1.32 \%$ \\
\hline Saturday & $3.05 \%$ & $2.24 \%$ \\
\hline Sunday & $2.45 \%$ & $3.29 \%$ \\
\hline
\end{tabular}

A. Double Seasonal Holt-Winters with exponential Smoothing

As discussed, the Holt-Winters variation performed well in forecasting Irish Supplier data, using only historical date to generate forecasts. Although the resulting MAPE was higher and not deemed acceptable for the National data, the forecast did follow the same shape as the load with the greatest discrepancies in the peaks and troughs. With this method, Supplier forecasts tend to be more accurate during the week with MAPEs as low as $1 \%$ in this data set. MAPEs are generally higher at the weekend with this method, typically above $2.5 \%$.

The method also performs better in the early hours of the morning, with many of the morning forecasts resulting in MAPEs below $2 \%$. For this research, the forecasts began at 00:00; considering the results of the first few half-hour forecasts, further work could examine the accuracy of forecasts at different hours of the day, starting forecasts from different times, e.g. 08:00, 12:00, 16:00 and 20:00.

\section{B. Neural Network}

The Neural Network method had very good $(2.18 \%$ MAPE) results with the Supplier data, as well as the National data $(2.35 \%)$. Notably, the $\mathrm{NN}$ produced more accurate 
forecasts when the original data were used for the National and the Supplier forecasts, rather than the smoothed data taking holidays etc. into consideration.

Like with the Holt-Winters Method, the Neural Network method had higher MAPEs in the middle of the week, reaching almost $4 \%$ on Wednesdays in the instance of the Supplier. The MAPE was also slightly higher on Fridays as well (just above 3.5\%), though unlike the Holt-Winters method, the weekends had good results, with MAPEs on Saturdays and Sundays being just below 2.5\%.

Concerning the time of day in the results of the $\mathrm{NN}$ forecast, MAPEs were highest in the early hours of the day $(00: 00-09: 30)$ at some points going above $4 \%$ and in the evening $(20: 30-23: 30)$ just reaching $4 \%$.

The input combinations that produced the most accurate forecasts for the Supplier data and the National data both included: Period, Weekday, Previous Day Same Hour, Previous Week Same Hour, Previous 24 Hour Average Load. The best combination for the Supplier forecast also included Air Temperature, while the National forecast additionally included Wet Bulb Temperature and Sunshine Hours.

\section{Recommendations and Further Work}

As both methods offered good results for the Irish market, it would be logical to further authenticate the findings of this research. The Neural Network model worked well for Supplier data and best for the National data. As the supplier associated with this research only serves industrial and commercial customers, it would be of interest to test the model on data that includes, and also perhaps data that are limited to, residential customers.

With the results found in this particular study, it could make sense to use a combination of both methods if time and resources allowed. The NN had more accuracy for Fridays and Saturdays; if this holds true in further simulations the NN method could be used for these days and the Holt-Winters method for the remaining days. However, both methods show promising results. Choosing between the two should be down to the diversity of costumer types, what resources are available and what findings are gathered from future simulations.

Further work could be undertaken to see how the HoltWinters variation performs forecasting by the period of the day, rather than by the day. That is, arranging the historical data so that the forecasting formula produces the next 48 forecasts for the first period, second period and so on for the day. It would be interesting to see if the MAPE would decrease in this circumstance, especially for data types like the National load.

\section{REFERENCES}

[1] Gaelectric. (2016). Delayed:I-SEM - Gaelectric. [online] Available at: http://www.gaelectric.ie/gtams/delayedi-sem/.

[2] SEM Committee, (2014). Integrated Single Electricity Market (I-SEM) SEM Committee Decision on High Level Design. Single Electricity Market Committee. [online] SEM Committee, pp.1 - 20. Available at: $\mathrm{http}: / / \mathrm{www}$. semcommittee.eu/en/wholesale overview.aspx?article=d3c f03a9-b4ab-44af-8cc0-ee1b4e251d0f.

[3] SEM Committee, (2014). "ISEM High Level Design", Publications. Single Electricity Market Committee. [online] Available at: https://www.semcommittee.com/sites/semcommittee.com/files/mediafiles/SEM-14-085a\%20I-SEM\%20SEMC\%20Decision\%20on $\% 20$ HLD.pdf.

[4] Srivastava, A.K., Ajay Shekhar Pandey, and Devender Singh. "Shortterm load forecasting methods: a review". International Conference On Emerging Trends In Electrical Electronics And Sustainable Energy Systems. Institute of Electrical and Electronics Engineers, 2016. 130 138. Web.

[5] Mbamalu, G. and EI-Hawary, M. (1993). Load forecasting via suboptimal seasonal autoregressive models and iteratively reweighted least sqaures estimation. IEEE Transactions on Power Systems, [online] 8(1), pp.343 - $348 . \quad$ Available at: http://ieeexplore.ieee.org/document/221222/.

[6] Hsu, Y.Y. and Ho, K.L. (1992). Fuzzy expert systems: an application to short-term load forecasting. IEEE Proceedings C - Generation, Transmission and Distribution, [online] 139(6), pp.471 - 477. Available at: http://ieeexplore.ieee.org/document/173251/.

[7] Dash, P.K., Liew, A.C. and Rahman, S. (1996). Fuzzy neural network and fuzzy expert system for load forecasting. IEE Proceedings Generation, Transmission and Distribution, [online] 143(1), pp.106 114. Available at: http://ieeexplore.ieee.org/document/488069/.

[8] Hippert, H.S., Bunn, D.W. and Souza, R.C. (2005). Large neural networks for electricity load forecasting: are they over fitted. International Journal of Forecasting, [online] 21(3), pp.425-434. Available http://www.sciencedirect.com/science/article/pii/S016920700400130X.

[9] Srinivasan, D. (1998). Evolving artificial neural networks for short term load forecasting. Neurocomputing, [online] 23(1-3), pp.265 -276. Available at: http://www.sciencedirect.com/science/article/pii/S0925231298000745.

[10] Ku-Long, H. et al. (1990). Short term load forecasting of Taiwan power system using a knowledge-based expert system. IEEE Transactions on Power Systems, [online] 5(4), pp.1214 - 1221. Available at: http://ieeexplore.ieee.org/document/99372/.

[11] El Desouky, A.A., Aggarwal, R., Elkateb, M.M. and Li, F. (2001). Advanced hybrid genetic algorithm for short-term generation scheduling. IEEE Proceedings - Generation. Transmission and Distribution, [online] 148(6), pp.511 - 517. Available at: http://ieeexplore.ieee.org/document/968467/.

[12] Taylor, J. W. (2003). Short-term electricity demand forecasting using double seasonal exponential smoothing. The Journal of the Operational Research Society, [online] 54(8), pp.799 - 805. Available at: https://www.jstor.org/stable/4101650?seq=1\#page_scan_tab_contents. 
978-1-5386-2344-2/17/\$31.00 @2017 IEEE

Authorized licensed use limited to: Technological University Dublin. Downloaded on January 26,2022 at 16:09:43 UTC from IEEE Xplore. Restrictions apply. 